(NASA-TH-81164) THE CARBON ISOTOPE

\title{
The Carbon Isotope Biogeochemistry of the Individual Hydrocarbons in Bat Guano and the Ecology of Insectivorous Bats in the Region of Carlsbad, New Mexico
}

David J. Des Marais, J. M. Mitchell, W. G. Meinschein, and J. M. Hayes

February 1980

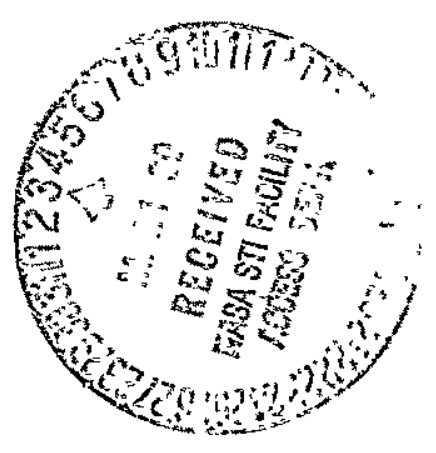




\section{The Carbon Isotope} Biogeochemistry of the Individual Hydrocarbons in Bat Guano and the Ecology of Insectivorous Bats in the Region of Carlsbad, New Mexico

David J. Des Marais, Ames Research Center, Moffett Field, California J. M. Mitchell

W. G. Meinschein

J. M. Hayes, Indiana University, Bloomington, Indiana

\section{N/SA}

National Aeronautics and

Space Administratıon

Ames Research Center

Moffett Field, California 94035 
The carbon isotope biogeochemistry of the individual hydrocarbons in bat guano and the ecology of insectivorous bats in the region of Carlsbad, New Mexico

DAVID J. DES MARATS

Ames Research Center, NASA, Moffett Field, California 94035, v.S.A.

and

J. M. MITCHELL, W. G. MEINSCHEIN*, and J. M. HAYES**

Department of Geology, Indiana University, Bloomington, Indiana 47405, U.S.A.

Abstract-The structures and ${ }^{13} \mathrm{C}$ contents of individual alkanes extracted from bat guano found in the Carlsbad region of New Mexico can be related to both the photosynthetic pathways of the local plants and the feeding habits of the insects that support the bats.

Carbon isotopic analyses of the 62 most important plant species in the Pecos River Valley, the most significant feeding area for the Carlsbad bats, reveal the presence of 29 species with C3 photosynthesis and 33 species, mostly grasses, with 64 photosynthesis. Although the abundances of nonagricultural $\mathrm{C} 3$ and $\mathrm{C4}$ plants are similar, alfalfa and cotton, both $C 3$ plants, constitute over 95 per cent of the crop biomass.

*Also School of Public and Environmental Administration, Indiana University, Bloomington, IN 47405.

**Also Department of Chemistry, Indiana University, Bloomington, IN $4740^{\circ} 5$. 
The molecular composition of the bat guano hydrocarbons is fully consistent with an insect origin. Two isotopically distinct groups of insect branched alkanes were discerned. These two groups of alkanes derived from two chemotaxonomically distinct populations of insects possessing distinctly different feeding habits. It is likely that one population grazes predominantly on crops whereas the other population prefers native vegetation. This and other isotopic evidence supports the notion that crop pests constitute a major percentage of the-bats' diet.

Because the guano sample was less than 40 years old, this material reflects the present day plant community in the Pecos River Valley. Future studies of more ancient guano deposits should reveal a measurable influence of both natural and man-induced vegetative changes with time upon the ${ }^{13} \mathrm{C}$ content of the bat guano hydrocarbons.

\section{INTRODUCTION}

Biogeochemical investigations and techniques can contribute to the delineation of the flows of carbon and other nutrients in ecosystems. Often, these details are inaccessible to other methods (e.g, direct observation, morphometric analysis). The vast majority of such biogeochemical studies has been concerned with aqueous environments (e.g, , RICHEY et al., 1978; FREDERICKS and SACKETT, 1970; DEUSER, 1971). Recently, several studies have appeared in the literature wherein the dietary preferences of certain terrestrial animals were elucidated by the ${ }^{13} \mathrm{C}$ analysis of plant and animal tissues (FRY et a1., 1978; BouTTON et a1., 1979; JONES et a1., 1979; DE NIRO and EPSTEIN, 1978). Such work 
was facilitated by the observation that herbivores reflected the carbon isotopic composition of their food source (HAINES, 1976; DE NIRO and EPSTEIN, 1978). In addition, the observation that C4, CAM, and C3 plants differed significantly in their ${ }^{13} \mathrm{C}$ contents (SMITH and EPSTEIN, 1971) provided biogeochemists with a natural spectrum of ${ }^{13} \mathrm{C}$ values within which the different dietary preferences of herbivores may be resolved.

This paper develops a new theme in the field of isotope biogeochemistry, namely that carbon isotopic analyses of individual hydrocarbons in feces provide a means for elucidating plant-herbivorecarnivore relationships. The present study involves the flow of carbon from plants through insects to bats in the Carlsbad region of New Mexico. At the beginning of this pathway, the photosynthesis fixation of carbon stores the energy that sustains, among other things, a diverse and seasonally variable insect population. Various species of migratory bats feed on the insects; they then take shelter in the local caves where they leave substantial guano deposits. Chemical analyses aimed at elucidating the relationships between these plant and animal communities could attempt to characterize all links of the food chain over a full year, but it is evident that this would be an enormous task and that the results could be severely affected by many different sources of variability. Indeed, it seems likely that such a "shotgun approach" would not yield any clear picture of the long-term average carbon flows. On the other hand, a Iimited suite of structural and isotopic analyses of the easily sampled inputs (plant material) and outputs (guano) would 
appear to offer significant opportunities. First, isotopic analyses of the plants provide information regarding the photosynthetically derived isotopic "labeling" of the input carbon flow. Second, investigation of the guano provides directly an appropriate time averaging of the conditions and populations involved. Finally, the resolution and analysis of individual alkanes in the guano allow characterization of details of the carbon flow far upstream from the final metabolic steps. This ability to retrace the steps of the carbon flow arises because alkanes, once formed, are not likely, to be modified in subsequent metabolic steps. Thus, for example, alkanes produced by the insects can pass unchanged through the bats to the guano, remaining there to provide evidence (through their structures) regarding the species of insects involved and (through their isotopic compositions) the plants eaten by the insects. The objectives of this work have been to demonstrate the capabilities of this line of investigation and to elucidate details of the carbon flow in this ecosystem.

The investigation of this somewhat unusual ecosystem is significant for at least three reasons. First, the lesser complexity of the ecosystem provides a useful first demonstration of the utility of molecular carbon isotopic analyses in studies of this kind. Second, although bats consume prodigious amounts of flying insects (see CONSTANTINE, 1970), morphometric analyses of stomach contents and guano have failed to give more than a general assessment of the importance of bats to agricultural pest control (CONSTANTINE, 1970). An accurate assessment of the effect of bats on agriculture would be timely, given the rapidly diminishing populations of these mammals in the United States COffice of Endangered 
Species and International Activities, 1973/ MOHR, 1976). Third, because thick guano deposits spanning thousands of years can be found in the Southwest, the isotope biogeochemistry of bat guano may help biologists to trace the evolution of plants and insects in a region whose climate does not favor the preservation of such information in aquatic sediments.

\section{EXPERTYENTAL}

Solvents were distilled and found to contain less than $10^{-9} \mathrm{~g} / \mathrm{ml}$ of impuricies with vapor pressure in the range of $\mathrm{n}^{-C_{14}}$ to $\underline{n}-\mathrm{C}_{40}$ alkanes. Glassware was cleaned at $110^{\circ} \mathrm{C}$ in a $2: 1$ mixture of concentrated sulfuric and nitric acids, rinsed in distilled water and tested methanol, and oven dried at $110^{\circ} \mathrm{C}$.

The bat guano was obtained from a cave in the Carlsbad region in Eddy County, New Mexico (MEINSChEIN, 1963). It was not determined which species of bat had deposited the guano that was examined in this study.

The procedures employed in the isolation and identification of the alkanes are depicted schematically in Fig. 1. A more detailed description of this procedure, except for the isotopic analyses, is given by MTTCHELL (1972). Aliquots of approximately $500 \mathrm{~g}$ of bat guano were extracted ultrasonically with $500 \mathrm{ml}$ of $9: 1(\mathrm{v} / \mathrm{v})$ benzene-methanol. Each. aliquot of guano received five sequential 5-min extractions using $500 \mathrm{ml}$ of benzene-methanol per extraction (MEINSCHEIN, 1963). Purified nitrogen was blown over the extract in a $40^{\circ} \mathrm{C}$ constant-temperature bath to remove a large portion of the solvent. The bulk alkanes were separated from the benzene-methanol extract by silica gel chromatography. 
About $9 \mathrm{~g}$ of 100- to 200-mesh commercial grade silica gel (Davison Company) was packed into columns $19 \mathrm{~cm}$ in length and $9 \mathrm{~mm}$ in diameter. Approximately 30 to $50 \mathrm{mg}$ of extract was added to the column, and the alkanes were eluted with $\underline{n}$-heptane.

A solution of $4 \mathrm{~g}$ of the alkanes that had been eluted from the silica gel was then refluxed in $200 \mathrm{ml}$ of benzene with $100 \mathrm{~g}$ of type $5 \mathrm{~A}$ molecular sieves (1.5-m pellets, Fisher Scientific Company) for $96 \mathrm{hr}$. The sieves were subsequently washed with six $50-\mathrm{ml}$ portions of benzene. The combined benzene washes plus the original supernatant solution were reduced to $200 \mathrm{ml}$; the occlusion process was repeated six times with fresh $100-g$ portions of molecular sieves. The nonoccluded alkanes were recovered from the filtrate of the seventh occlusion cycle. The molecular sieves were combined for recovery of the occluded alkanes, which were released by dissolution of the sieves in $650 \mathrm{ml}$ of 48 per cent hydrofluoric acid. The hydrofluoric acid had been extracted previously with benzene until the benzene wash contained less than $10^{-9} \mathrm{~g} / \mathrm{ml}$ of impurities with vapor pressure in the range of $\underline{n}-C_{14}$ to $n-C_{40}$ alkanes.. The suspension of disintegrated sieves was diluted to $3: 1$ with purified, distilled water, and the diluted suspension was successively extracted with eight 300-ml portions of benzene. The volume of these benzene extracts was reduced by evaporation at $40^{\circ} \mathrm{C}$ using the nitrogen stream.

The alkane fraction not occluded by molecular sieves was dissolved in $200 \mathrm{ml}$ of a $3: 2(\mathrm{v} / \mathrm{v})$ benzene-methanol solution which was saturated at room temperature with urea. An excess of $0.2 \mathrm{~g}$ of urea was added and dissolved by heating the solution. After, $24 \mathrm{hr}$, the urea crystals and adduct were recovered on sintered glass by filtration and washed 
with three 20-ml aliquots of cold benzene. The urea adduct crystals were then dissolved in 20-ml of distilled water and the released branched alkanes were extracted from'the water with five successive 30-mil portions of $\underline{n}$-heptane.

The mixtures of $\underline{n}$-alkanes and branched alkanes were fractionated by preparative gas-liquid chromatography $[8 \mathrm{~mm} i . \dot{i} . \times 120 \mathrm{~cm}$ glass column packed with $10 \mathrm{w}$ to \% W-98 silicone (Applied Science Laboratories) on 45-60 mesh Chromosorb $\mathrm{W}$, column temperature programmed from $100^{\circ} \mathrm{C}$ to $360^{\circ} \mathrm{C}$ at $1^{\circ} / \mathrm{min}, 300 \mathrm{ml} / \mathrm{min} \mathrm{N}_{2}$-carrier-gas flow]. The effluent was split 100:1 to permit simultaneous detection by flame ionization detector and collection of the alkanes in traps made according to the design of BLOOMER and EDER (1968). Each branched alkane peak obtained via preparative gas chromatography was separated further on a $15-m$ by $8-\mathrm{mm}$ i.d. coiled column packed with alumina (Woelm neutral, chromatographic activity grade 1). The alumina column was washed with 10 liters of $\underline{\text { n-heptane }}$ prior to initial use and with 3 liters of $\underline{n}$-heptane between successive runs of alkane fractions. The column was pressurized with.100 psig nitrogen to facilitate elution. Each alkane fraction was eluted with 2-5 liters of $\underline{n}$-heptane and the eluant was collected in 10-ml aliquots using an automatic fraction collector. The aliquots containing alkanes with the same gas chromatographic retention times were combined.

Each of the resolved $\underline{n}$-alkane and branched alkane fractions was analyzed by GCMS [CEC 21-1106 mass spectrometer, fritted-glass separator (WATSON and BIEMANN, 1964), 3-mm i.d. × 200-cm glass column packed wi.th 3 wt. \% GC grade SE-30 silicone (Applied Science Laboratories) on 100-120 mesh Gas Chrom Q, isothermal column temperatures ranging 
between $220^{\circ} \mathrm{C}$ and $340^{\circ} \mathrm{C}$ as required for each fraction, $20 \mathrm{ml} / \mathrm{min}$ Hecarrier-gas flow]. When possible, spectra were matched with those of authentic standards. If members of a homologous series lacked available standard spectra, identifications were based on behavior during the isolation procedure, gas chromatographic retention time, and comparisons with mass spectra of closely related materials. Approximately 80 per cent of the total alkane fraction was identified.

Prior to carbon isotope analysis, each alkane fraction or plant sample was converted to $\mathrm{CO}_{2}$ using a combustion system fitted with a quartz oven tube containing a platinum catalyst. The combustions were performed in oxygen at 50 torr and at $1000^{\circ} \mathrm{C}$. During a typical analysis, the combustion blank weight, the alkane preparation blank weight (contributed by solvents, preparative chromatographic column bleed, etc.), and the sample weight were $0.3 \mu g,<2 \mu g$, and $40 \mu g$, respectively. The carbon dioxide' product was separated from water using a $-140^{\circ} \mathrm{C}$ cold trap similar to that described by DES MARAIS (1978). The purified carbon dioxide was transferred to the inlet system of a Varian model GD150 mass spectrometer. The $\delta^{13} \mathrm{C}$ values are reported relative. to the $\mathrm{PDB}$ marine carbonate standard, and uncertainties for each $\delta^{13} \mathrm{C}$ result are reported as one standard deviation.

\section{RESULTS AND DISCUSSION}

\section{Carbon isotope distribution in plants of the Pecos River Valley}

Carlsbad area bats prefer to forage for their prey principally along the Pecos River Valley (BARBOUR and DAVIS, 1969), because the 
relatively abundant vegetation of this area supports a larger population of insects than do the adjacent uplands. Accordingly, the carbon isotopic compositions of the plant species in this valley were determined (Tables 1 and 2). All analyses were performed on either young leaves or grass blades where possible, rather than on stems or roots, because it was expected that these parts are generally preferred by the insects. Furthermore, LERMAN (1975) stressed that different parts of a plant can have different ${ }^{13} \mathrm{C}$ contents. Therefore, the most consistent comparison of plant $\delta^{13} \mathrm{C}$ values is achieved by analyzing similar plant organs. The following observations can be made from the data in Tables 1 and 2:

1. Among the 58 nonagricultural plant species listed in Table 1, there is a bimodal ${ }^{13} \mathrm{C}$ distribution (Fig. 2a), with 31 isotopically "heavy" species (in the range -10 to -20 permil) and 27 isotopically "Iight" species (in the range -20 to -35 permil), reflecting the plant populations with C3, C4, and CAM photosynthetic pathways (see SMITH and BROWN, 1973). Among the 13 species considered to be dominant in this ecosystem (BURGESS, 1978), 8 are isotopically "heavy" C4 and CAM species and 5 are isotopically "light" C3 species.

2. Grasses utilizing the $\mathrm{C} 4$ photosynthetic pathway dominate the ${ }^{13} \mathrm{C}$-enriched plant population in this ecosystem. Twenty-seven of the $31^{13} \mathrm{C}$-enriched species are grasses, and 7 of the 8 dominant "heavy" species are grasses. Twentymseven of the 29 grass species, including a11 7 dominant grasses, utilize the 64 pathway.

3. Of the four principal summer-season crops in Eddy County, New Mexico, the two dominant crops, alfalfa and cotton (New Mexico 
Agricultural Statiștics, 1977), are C3 plants, Because alfalfa and cotton occupy more than 20 times the area (see Table 2) devoted to corn and sorghum, which are both $C 4$ plants, the biomass consumed by insects feeding on crops in this region is ${ }^{13} \mathrm{C}$-depleted relative to the native plant biomass.

Molecular and carbon isotope distributions in Carlsbad bat guano

The benzene-methanol extract of $45.5 \mathrm{~kg}$ of bat guano weighed $72.3 \mathrm{~g}$. The total alkane fraction isolated from this extract by silica gel chromatography weighed $5.7 \mathrm{~g}$. A radiocarbon/analysis of a portion of these alkanes (sample GX-6382, Geochron Laboratories, Cambridge, Massachusetts) revealed the presence of excess ${ }^{14} \mathrm{C}$ produced by atmospheric nuclear weapon testing. The presence of this ${ }^{14} \mathrm{C}$ indicates that the guano is less than $40 \mathrm{yr}$ old. Tables 3 and 4 summarize the structures, concentrations, and carbon isotopic compositions of the bat guano alkanes that have been characterized.

The n-alkane series (Table 3 ) extends from $\mathrm{C}_{15}$ through $\mathrm{C}_{43}$, with the $C_{15}$ through $C_{20}$ and the $C_{42}$ and $C_{43}$ hydrocarbons comprising less than 1 per cent of the total. In the vicinity of $C_{29}$, where the hydrocarbons were most abundant, the mixture had an odd-even preference (OEP) of 6 (SCALAN and SMIITH, 1970). The ${ }^{13} \mathrm{C}$ abundances of these alkanes were in the range -22.2 to -26.1 permil (versus PDB) with a weighted mean value of -23.6 permil. Closer examination of the $\delta^{13} \mathrm{C}$ values in Table 3 reveals that the odd-carbon-number n-alkanes are, as a group, enriched in ${ }^{13} \mathrm{C}$ relative to the even-carbon-number alkanes. For reasons discussed later, this pattern can be interpreted as indicating multiple sources of the n-alkanes in the guano. 
The branched chain hydrocarbons constitute more than 50 per cent by weight of the alkanes identified by MITCHELL (197.2). The molecular weight distributions of the isoalkanes and internally branched alkanes are 1isted in Table 4. Internally branched monomethylalkanes were Identified as mixtures of four or five isomers for each of the even carbon numbers from $\mathrm{C}_{26}$ to $\mathrm{C}_{36}$. The internally branched dimethyl substituted alkanes were characterized as mixtures of two to four isomers occurring at each of the odd carbon numbers from $\mathrm{C}_{35}$ through $\mathrm{C}_{51}$. The ${ }^{13} \mathrm{C}$ values of the branched alkanes ranged from -19.6 to -24.8 permil, with a weighted mean of $-21 . \dot{9}$ permil. There is no significant difference between the mean unweighted isotope ratio of the monomethyl branched hydrocarbons (-22.2 permi1). However, as shown in Fig. 2c, a pronounced bimodal distribution appears when the isotopic compositions of individual branched hydrocarbons are considered.

This observation, together with a noticeable bimodality in the abundances of the dimethyl branched hydrocarbons (Table 4 and Fig. 3), indicates that the branched hydrocarbons derive from multiple sources. The Carlsbad area bats and the origin of the guano hydrocarbons

Evidence presented in this section indicates that the major fraction of the hydrocarbons in the guano derives from insects consumed by the bats. Most bats of the Carlsbad region are migratory; they inhabit the caves during the spring, summer, and fall seasons. The Insectivorous bats Tadartda brasiliensis and Myotis velifer are dominant in the Carlsbad area, and are accompanied by smaller populations of the genera Antrozous, Eptesicus, Lasionycteris, Lasiurus, Pipistrellus 
and Plecotus (BARBOUR and DAVIS, 1969). ROSS (1967) determined the dietary preferences of numerous insectivorous bat species in the southm western United States. The percentages of insect orders preferred by Tadarida brasiliensis were as follows: Lepidoptera, 34; Hymenoptera, 26.2; Coleoptera, 16.8; and Homoptera, 15. The percentages of insect orders preferred by Myotis velifer were as follows: Coleoptera, 54.9; Lepidoptera, 37.2; and Homoptera, 5.0. In summary, the insect preferences of the Carlsbad area's dominant bat populations are Lepidoptera, 36 per cent; Coleoptera, 36 per cent; Hymenoptera, 13 per cent; and Homoptera, 10 per cent.

No hydrocarbon analyses have been reported for the prey in Tadarida and Myotis, but published analyses of hydrocarbons in insects indicate an appreciable structural overlap among alkanes isolated from various insect species (see JACKSON and BLOMQUIST, 1976). Abundant n-alkanes are found in the range $\mathrm{C}_{23}$ to $\mathrm{C}_{31}$; abundant isoalkanes are at $\mathrm{C}_{29}$ and $\mathrm{C}_{31}$; abundant anteisoalkanes are at even caxbon numbers from $\mathrm{C}_{24}$ to $\mathrm{C}_{30}$; significant concentrations of mononethyl internally branched alkanes are predomin-ately at even carbon numbers from $\mathrm{C}_{24}$ to $\mathrm{C}_{40}$; and significant amounts of dimethyl hydrocarbons occur at all odd carbon numbers between $C_{35}$ and $\mathrm{C}_{47}$. These distinctive patterns closely match those shown in Tables 3 and 4. No other known natural source produces such an abundant array of high-molecular-weighted branched hydrocarbons. Plants produce very minor amounts of branched alkanes (TULLOCH, 1976), and bacteria or fungi, perhaps including those that undoubtedly grow in the guano, synthesize branched hydrocarbons with carbon numbers chiefly in the $c_{20}$ to $c_{30}$ range or lower (WEETE, 1976; ALBRO, 1976). The beetles Dermestes 
carnivorous (CONSTANTINE, 1970) and Alphitobius diaperius (DAVIS et al., 1962) occupy the guano deposits in the Carlsbad region and likely contributed a small percentage of the branched hydrocarbons to the guano. Therefore, insects consumed by the bats produced essentially all the branched hydrocarbons found in the guano.

Because many organisms produce n-alkanes (KOLATTUKUDY, 1976), the guano n-alkanes probably derive from more sources than do the branched hydrocarbons. For example, although insects alone synthesize the specific high-molecular-weight branched hydrocarbons identified here, evidence exists that they can assimilate $\underline{n}$-alkanes from their plant diet into their exoskeletons (JACKSON and BLOMQUIST, 1976). Therefore, the synthesis of the n-alkanes found in the guano has probably occurred both in plants and in the insects. A mixture from these two sources of n-alkanes may give rise to the observation, noted earlier, that the odd-carbon-number n-alkanes are isotopically heavier as a group than the even-carbon-number n-alkanes. A comparison of both the insect hydrocarbon data summarized by JACKSON and BLOMQUIST (1976) and the plant data reviewed by TULLOCH (1976) indicates that insects genera11y

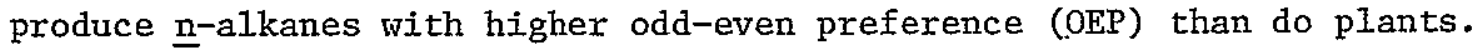
Perhaps the odd-even isotope pattern in the guano reflects a proportionately greater contribution by plant biosynthesis to the evennumbered guano $\mathrm{n}$-alkanes. If so, it indicates that the alkanes produced by de novo biosynthesis within the insects are enriched in ${ }^{13} \mathrm{C}$ relative to the alkanes synthesized in the plants. This notion is supported by considerations outlined in the discussion below, 
Carbon isotopic evidence concerning insect herbivory in the Carlsbad area bat ecosystem

In their recent study of the influence of diet on the distribution of carbon isotopes in animals, DE NIRO and EPSTEIN (1978) found that "the isotopic composition of the whole body of an animal reflects the isotopic composition of tes diet, but the animal is on average enriched in $\delta^{13} \mathrm{C}$ by about one permil relative to the diet." From these observations it appears reasonable that the isotopic composition of the insect remains in the guano should reflect the isotopic composition of the plants in the Carlsbad area which constituted the insects' diets. The objective of this section is to compare the isotopic analyses of the Carlsbad-area plants with those of the guano hydrocarbons to discern the dietary preferences of the insects.

It is necessary first to evaluate any isotopic discrimination that may occur as carbon flows from the plants to the guano. The steps in this process are schematically represented in Fig. 4, which in order to establish a basts for discussion of the present results, represents the expected (not actually measured) sequence of carbon isotopic fractionations in a highly simplified system involving a single plant and a single insect. Within the plant, the primary control over isotopic composition is exerted by the carbon-fixing process itself, as discussed in connection with Tables 1 and 2 and Fig. 2a. Here, for purposes of illustration, it will be assumed that this photosynthetic fractionation has established the isotopic composition of the whole plant at $\delta^{13} \mathrm{C}_{\mathrm{PDB}}=-25.0$ permil. An additional fractionation accompanies the biosynthetic production of 
alkanes and other lipids. DE NIRO (1977) found that the lipids in 18 higher plants were depleted in ${ }^{13} \mathrm{C}$ by an average of 6.3 permil.

$(S D=2.5$ permil $)$ relative to the total plants, and this average depletion has been arbitrarliy assigned to "plant alkanes" in Fig. 4.

Additional isotopic fractionations and biosynthetic processes should occur within the insects. In the specific case of moths (Desmia) fed grape leaves, DE NIRO (1977) found that the whole insects were enriched in ${ }^{13} \mathrm{C}$ relative to their diet by approximately 2 permil. This fractionation is represented in Fig. 4 together with an indicated $I$ permil depletion of ${ }^{13} \mathrm{C}$ in insect-synthesized alkanes. The magnitude of the latter fractionation can be estimated on the following basis:

1. In the present work, it has been observed that the internally. methyl-branched alkanes (which must be derived only from insect biosynthesis) are 1.8 permil depleted in ${ }^{13} \mathrm{C}$ relative to the total guano (Table 5).

2. Animal feces are generally 0.8 permil enriched in ${ }^{13} \mathrm{C}$ relative to the diet (DE NIRO, 1977; four observations, $S D=0.5$ permil. 3. Therefore, it would appear that insects like those involved in the present study could be expected to produce alkanes depleted in ${ }^{13} \mathrm{C}$ relative to their diet by about 1 permil, this biosynthetic fractionation being required to explain the observed 1.8 permil difference. between branched alkanes and the total guano. This estimate is consistent with DE NIRO's (1977) finding that the lipids of most multicellular heterotrophic organisms are between 1 and 5 permil depleted in ${ }^{13} \mathrm{C}$ relative to the total organisms. 
The expected distribution of ${ }^{13} \mathrm{C}$ among carbon reservoir of interest in the insects is indicated in Fig. 4. The normal alkanes, which are expected to be derived in part from de novo biosynthesis within the insects and in part from the assimilation of plant alkanes (JACKSON and BLOMQUIST, 1976), should have an isotopic composition representative of this dual origin. In this example, it has been arbitrarily assumed that the odd-carbon-number n-alkanes derive primarily (67 per cent) from insect biosynthesis and that the even-carbon-number n-alkanes derive primarily (67 per cent) from plant blosynthesis. This assumption is generally consistent with the observation that, relative to odd-carbonnumber $\underline{n}$-alkanes, even-carbon-number n-alkanes are more abundant in plants than in insects (JACKSON and BLOMQUIST, 1976; TULLOCH, 1976).

Finally, it is expected that the metabolic processes of the bats will not affect the isotopic compositions of the alkanes but that (see item (2) above) the guano will be enriched in ${ }^{13} \mathrm{C}$ relative to the total insects by approximately 0.8 permil.

An interpretation of the results of the present study, which involves a complicated natural system containing many. species at each trophic level, can be based on the expected fractionations outlined in Fig. 4. In this case, it is necessary, to begin with the observed isotopic compositions of the guano alkanes and to work backward through the carbon pathway in some way that leads to a satisfactory accomnodation with the known isotopic compositions of the plants that must have furnished the input carbon.

Because multiple sources probably exist for the normal alkanes, we can utilize only the branched hydrocarbon data for our comparisons 
between isotopic compositions for the guano hydrocarbons and the plants. The data in Fig. 3 indicate that these branched hydrocarbons derive from a variety of insects with a variety of dietary preferences. The hydrocarbons produced by a given insect are expected to have uniform isotopic compositions (PARKER, 1964; HOERING, 1975). In addition, one species of insect typically produces in abundance only one or two members of a given homologous series of branched chain hydrocarbons. Using the hydrocarbon data compiled for 17 insect species (JACKSON and BLOMQUIST, 1976), we noted that, for a given insect, the two most abundant branched alkanes of a homologous series constituted $83 \pm 13$ per cent (one standard deviation) of the total alkanes synthesized in that series. Given the wide variety of flying insect species available to the bats during a summer season, it is no surprise that the complex hydrocarbon pattern depicted in Fig. 3 is observed. Furthermore, because it is anticipated that the numerous insects would exhibit a spectrum of dietary preferences, one might expect to observe a population of alkanes with a smooth continuum of $\delta^{13} \mathrm{C}$ values. It is surprising, therefore, that a plot of numbers of branched alkanes versus their ${ }^{13} \mathrm{C}$ content (Fig. 2c) yields a pronounced bimodal distribution. This distribution must describe two insect populations that differ both in their diets and in the molecular composition of their branched hydrocarbons. The relationships between the isotopic compositions of the branched alkanes and the dietary preferences of the two insect populations are summarized in Fig. 5a. The heavier branched alkanes ("branched alkanes I", $\delta=-20.2$ permil) must relate to insects slightly more enriched in ${ }^{13} \mathrm{C}$ ("whole insects $\mathrm{I}$," $\delta=-19.2$ permil. As noted in Fig. 4 and in the accompanying discussion, that 
insect population must, in turn, relate to a net dietary input 2 permil depleted in ${ }^{13} \mathrm{C}\left(" \mathrm{I}^{\mathrm{n}}\right.$ in the "inferred diet" column of Fig. 5a). A similar sequence of logical steps shows that the insects responsible for the production of the lighter branched alkanes must have preferred plants with a weighted average isotopic composition ("II" in the "inferred diet" column, Fig. 5a) very near that of the 03 plants in this locality. The relative abundances of these two insect populations and the relative contributions of each plant type to their diets can be estimated quantitatively. The weighted average isotopic composition of the bats $^{3}$ diet can be estimated as shown in Fig. 5a, and the fractional contributions of each insect population to that diet can be determined by the use of an approximate mass balance expression

$$
\alpha_{I} \delta_{I}+\left(1-\alpha_{I}\right) \delta_{I I}=\delta_{d}
$$

where $\alpha_{I}$ is the fraction of the bats' diet made up of insects having an isotopic composition $\delta_{I}$, the remainder of the diet is made up of insects having an isotopic composition $\delta_{I I}$, and $\delta_{\mathrm{d}}$ is the isotopic composition of the net dietary input. Inserting $\delta_{I}=-19.2$ permil, $\delta_{I I}=-22.7$ permil, and $\delta_{d}=-20.9$ permil, the result, $\delta_{I}=0.51$, is obtained, indicating that the two insect populations contribute equally to the bats' diet. Similar calculations show that insect population I derives $\sim 37$ per cent of its diet from 44 or CAM plants and that insect population II derives only $\sim 10$ per cent of its diet from those sources. The significance of these preferences can be discussed in some detail, but it is of interest, first, to consider the origins and isotopic compositions of the normal alkanes isolated from the guano. 
Pathways possibly representative of the dual origins of the guano n-alkanes are outlined in Fig. 5b. Because there is no structural basis for separating the insect-derived and plant-derived n-alkanes, it is possible only to show pathways that are consistent with, rather than explicitly identified with, the isotopic compositions of the $\underline{\text { n-alkanes. }}$ The odd- $\mathrm{n}$ and even-n populations found in the guano can each be split into two precursor groups which are assumed to differ by 3.5 permil while contributing equally to the guano (that is, these precursor n-alkane families are assumed to be related to each other and to the guano n-alkanes in the same way that the "whole insects I" and "whole insects II" populations are related to each other and to the bats' diet). As shown in Fig. 5b, each of these precursor n-alkane families must be "assembled" from both plant and insect sources. In each case, the plantderived alkanes are themselves a mixture. In Fig. 5b, the relative $\mathrm{C3}$ and $C 4$ contributions have been calculated using the $37: 63$ and 10:90 mixing ratios deduced in the discussion accompanying Fig. 5a. When this is done, it is found that the odd-carbon-number n-alkanes (in both populations I and II) are $\sim 79$ per cent insect-derived and $\sim 21$ per cent plant derived, and that the even-carbon-number $\underline{n}$-alkanes are $\sim 63$ per cent insect-derived and $\sim 37$ per cent plant-derived. Although no great confidence can be placed in the quantitative accuracy of these calculations, they are consistent with the known characteristics of plant and insect distributions of odd versus even carbon number $\underline{n}$-alkanes (JACKSON and BLOMQUIST, 1976; TULLOCH, 1976) and probably represent a useful refinement of purely qualitative statements. 
Concerning the bimodal distribution of branched alkanes, a number of explanations could be offered for the appearance of two isotopically distinct populations of insect remains in the bat guano. Perhaps these populations represent the different insect orders in the bats' diets. For example, given the dietary data listed earlier, the Lepidoptera (mioths) could constitute one group and the Coleop'tera (beetles) the other group. These two orders could certainly be chemotaxonomically distinct with respect to their branched alkane structures. However, it is surprising that the presence of the other orders represented, namely the Hymenoptera and Homoptera, would not obscure this bimodal distribution. Furthermore, given the tremendous varieties of species and their herbivory which are represented in each of these orders, it has not been observed that order Lepidoptera, for example, would select diets whose C3 plant content differed substantially from the diets of Coleoptera or any other insect order (GHOLSON, 1979).

Another explanation for the presence of two distinct insect populations is that one population consists of native insects consuming predominantly native vegetation and that the other population consists. of native species and species imported to the Carlsbad area by man, the latter two groups of species preferring the crops to the native vegetation. Significant agricultural pests can be found in Family Noctuidae (miller moths), which are night-flying and therefore potential bat prey. These insects include Euxoa auxiliaris (army cutworm), Heliothis zea (cotton bol1worm) and Spodoptera exigua (beet armyworm) (APIS, 1979). As their common names imply, these agricultural pests . should consume a greater percentage of farm crops than would most native 
insects, which are better adapted to the native vegetation. The crop biomass contains a substantially greater percentage of $c 3$ plants (over 90 per cent, Table 2) than does the nonagricultural plant biomass (below 50 per cent, estimated fron the $\delta^{13} \mathrm{C}$ values of the dominant species listed in Table 1). Given this contrast, the insects consuming mainly crops would be isotopically lighter than the insects that select native vegetation, and these two groups can be tentatively identified with insect populations II and I (Fig. 5a), respectively. It could be speculated that, because some of the crop pests are species imported to the area, all but their most recent evolutionary history occurred elsewhere and, as a result, their alkanes differ from those of the native populations. Alternatively, the pests may dominate the crop grazing because they possess different, better adapted bodily features; and these differences happen to coincide with differences in the insects' complements of branched alkanes. In either case, the coupling between alkane structures and food preferences might be a quite general phenomenon, indicating that this mode of investigation might be broadly applicable.

One test of the hypothesis that crop cultivation has produced a second, isotopically distinct population of branched alkanes would be to examine guano that had been deposited prior to the advent of agriculture in the Pecos River Valley: A solitary hydrocarbon peak in a diamgram such as Fig. 2c, with a mean $\delta^{13} \mathrm{C}$ value in the vicinity of the mean value for the native vegetation, would support the notion that the second, isotopically lighter peak in Fig. 2c derives from crop pests. If this could be demonstrated, then perhaps native and agricultural. 
insect populations could be discerned isotopically in other farming regions where the mean $\delta^{13} \mathrm{C}$ value of the native vegetation differs from the mean value of the nonnative crops by several permil.

\section{Significance of bats as predators of agricultural pests}

Calculations based on the feeding habits of bats and their populations in the Southwestern U.S. Indicate that these mamals consume prodigious amounts of flying insects (see CONSTANTINE, 1970). Previous data concerning bat diets obtained from morphometric analyses of stomach contents and guano, have been inadequate to give more than a general assessment of the importance of insectivorous bats to agricultural pest control (CONSTANIINE, 1970). The present analyses suggest that agricultural insect pests may constitute a substantial percentage of the bats' prey. If, as proposed in the previous section, the remains of such insects produced the isotopically lighter group of branched alkanes, then these pests constitute approximately half of the bats' diet. Additional support for the notion that bats consume a substantial proportion of crop insects is provided by the mean $\delta^{13} \mathrm{C}$ values of the nonagricultural biomass ( -19.2 permil), crops ( -26 permil) and the overall insect diet $(\sim-23$ permil, Fig. 5a). Because the latter number is halfway between the mean crop value and the mean native plant value, it implies that bats consume insects that (overa11) select crops as frequently as native vegetation during the warm seasons.

An alternative explanation for the isotopically light value calculated for the consumed plants is that the insects are avoiding C4 plants (for example, see CASWELL et al., 1973). Such a pronounced 
avoidance of $\mathrm{C} 4$ plants is not supported by the work of BOUTTON et al. (1979.), however, who did not note marked differences in utilization of C3 and $\mathrm{C}_{4}$ grasses, although they did note a statistically heavier utilization of C3 species when $\mathrm{C} 3$ and $\mathrm{C} 4$ groups of grasses were compared. Such findings perhaps reflect a depression of grazing on the $\mathrm{C} 4$ grasses due to a preference for $\mathrm{C3}$ material, but certainly not an absolute avoidance of 64 material. Because one insect population does apparently avoid $\mathrm{G} 4$ material, this must be attributable to the fact that essentially all the $\mathrm{C} 4$ material is derived from grasses. The avoidance, therefore, reflects a preference for nongrass species for reasons other than simply the C3-C4 criterion. As summarized by BOUTTON et al. (1979), insects exhibit dietary preferences based on plant morphology, chemistry, growth habit, etc. The hydrocarbon ${ }^{13} \mathrm{C}$ data constitute evidence for such discrimination. Therefore, native and non-native (crop) plants may constitute two distinct plant populations whose differences have supported a distinct bimodality in the local populations of herbivorous insects. Bat guano as a paleoecologic record

Vegetation in the Southwestern U.S. has changed during the past 20,000 yr in response to climate (VAN DEVENDER and SPAULDING, 1979). Given the evidence in this paper, one can anticipate that variations with time in mean ${ }^{13} \mathrm{C}$ abundances of vegetation, reflecting varying abundances of $\mathrm{C} 3$, C4, and CAM plants, should have caused shifts in the ${ }^{13} \mathrm{C}$ content of bat guano hydrocarbons. The $C_{4}$ and CAM photosynthetic strategies are better suited to sunny, semiarid environments than is $\mathrm{C3}$ photosynthesis (see, e.g., WOOLHOUSE, 1978). As noted in this work, grasses in the Pecos 
River Valley today are dominantly 64 plants. Analyses of ancient guano deposits may reveal whether such dominance persisted during the cooler, wetter periods of Pleistocene history.

Acknowledgments-The authors are grateful to Mr. Tony Burgess, University of Arizona, for the native plant samples and for an estimate of their relative abundances in the Pecos River Valley: We are also indebted to Larry Gholson, New Mexico Cooperative Extension Service, for the crop samples from Eddy County and for helpful discussions.' We acknowledge the valuable laboratory assistance of David $0^{\prime}$ Neill and Jason Donchin (ARC). The' work at Indiana University was supported by NASA grant NGR-15-003-118. 
REFERENCES

ALBRO P. W. (1976) Bacterial waxes. In Chemistry and Biochemistry of Natural Waxes, (editor P. E. Kolattukudy), E1sevier, 419-445.

APIS (Animal and Plant Health Inspection Service) (1979) Cooperative PIant Pest Reports. U.S. Department of Agriculture, Hyattsville, Maryland, June-September issues.

BARBOUR R. W. and DAVIS W. H. (1969) Bats of America. University Press of Kentucky, Lexington.

BLOOMER J. L. and EDER W. R. (1968) A simple and efficient collector for gas chromatography. J. Gas Chromatogr. 6, 448 .

BOUTTON T. W., CAMERON G. N., and SMITH B. N. (1979) Insect herbivory on C3 and C4 grasses. Submitted to Decologia.

BURGESS T. (1978) University of Arizona. Personal communication. CASWELL H., REED F., STEPHENSON S. N. and WERNER P. A. (1973) Photosynthetic pathways and selective herbivory: a hypothesis. Amer. Nat. $107,465-480$.

CONSTANTINE D. G. (1970) Bats in relation to the health, welfare and economy of man. In Biology of Bats II, (editor W. Wimsatt), Academic Press, New York, 319-449.

DAVIS R. B., HERREID C. F., JR, and SHORT H. I. (1962) Mexican free tailed bats in Texas. Ecol. Monogr. 32, 311-346. 
DE NIRO M. J. (1977) I. Carbon isotope distribution in food chains.

II. Mechanism of carbon isotope fractionation associated with 1ipid synthesis. Ph.D. dissertation, California Institute of Technology, Pasadena, California.

DE NIRO M. J. and EPSTEIN S. (1978) Influence of diet on the distribution of carbon isotopes in animals. Geochim. Cosmochim. Acta 42, 495-506. DE NIRO M. J. and EPSTEIN S. (1978) Carbon isotopic evidence for different patterns in two Hydrax species occupying the same habitat. Science 201 (4359), 906-908.

DES MARATS D. J. (1978) Variable temperature cryogenic trap for the separation of gas mixtures. Ana1. Chem. 50, 1405-1406.

DEUSER W. G. (1971) Organic carbon budget of the Black Sea. Deep Sea Res. $18,995-1004$.

FREDERTCKS A. D. and SACKETT W. M. (1970) Organic carbon in the Gulf of Mexico. J. Geophys. Res. 75 (12), 2199-2206.

FRY B., JENG W. L., SCALAN R. S., PARKER P. L. and BACCUS J. (1978) $\delta^{13} \mathrm{C}$ food web analysis of a Texas sand dune community. Geochim. Cosmochim. Acta 42 (8), 1299-1302.

GHoLsON L. (1979) New Mexico Cooperative Extension Service, Southeastern Branch. Pexsonal communication.

HAINES E. B. (1976) Relation between the stable carbon isotope composition of fiddler crabs, plants and soils in a salt marsh. Itimol. Oceanogr. $21,880-883$. 
HOERING T. C. (1975) The biogeochemistry of the stable hydrogen isotopes. In Carnegie Institute of Washington, Annual Report of the Geophysical Laboratory, 1974-1975, 598-604.

JACKSON L. L. and BLOMQUIST G. J. (1976) Insect waxes. In Chemistry and Biochemistry of Natural Waxes, (editor P. E. Kolattukudy), E1sevier, 201-233.

JONES R. J., LUDLOW M. M., TROUGHTON J. H. and BLUNT C. G. (1979) Estimate of the proportion of C3 and C4 plant species in the diet of animals from the ratio of natural ${ }^{13} \mathrm{C}$ and ${ }^{12} \mathrm{C}$ isotopes in the feces. J. Agr. Sci. 92, 91-100.

LERMAN J. C. (1975) How to interpret variations in the carbon isotope ratio of plants: biological and environmental effects. In Environmental and Biological Control of Photosynthesis, (editor R. Marcelle), Dr. W. Junk b.v., The Hague, The Netherlands.

KOLATTUKUDY P. E. (1976) Chemistry and Biochemistry of Natural Waxes. Elsevier.

MEINSCHEIN W. G. (1963) Development of hydrocarbon analyses as a means of detecting life in space. Quarter1y Report, Apri1 1, 1963, Contract No. NASW-508.

MITCHELL J. M. (1972) The geochemical significance of the alkanes in bat guano. Ph.D. dissertation, Indiana University, Bloomington, Indiana.

MOHR C. E. (1976) The World of the Bat. J. B. Lippincott, Philadelphia. 
New Mexico Agricultural Statistics (1977). U.S. Department of Agriculture and New Mexico Department of Agriculture, Las Cruces, New Mexico.

Office of Endangered Species and International Activities (1973)

Threatened Wildlife of the United States. U.S. Government Printing Office, Washington, D.C.

PARKER P. L. (1964) The isotopic composition of the carbon of fatty acids. In Garnegie Institute of Washington, Annual Report of the Geophysical Laboratory 1963-1964, 187-190.

RICHEY J. E., WISSMAN R. C., DEVOL A. H., LIKENS G. E., EATON J. S., WETZEL R. G., ODUM W. E., JOHNSON N. M., LOUCKS O. L., PRENTKI R. T. and RICH P. H. (1978) Carbon flow in four lake ecosystems: a structural approach. Science 202, 1183-1186.

ROSS A. (1967) Ecological aspects of the food habits of insectivorous bats. Proc. West. Found. Vertebrate Zoó1. 1, 205-263.

SCALAN R. S. and SMITH J. E. (1970) An improved measure of the odd-even predominance in the normal alkanes of sediment extracts and petroleum. Geochim. Cosmochim. Acta 34, 611-620.

SMITH B. N. and EPSTEIN S. (1971) Two categories of ${ }^{13} \mathrm{C} /{ }^{12} \mathrm{C}$ ratios for higher plants. Plant Physiol. 47, 380-384.

SMITH B. N. and BROWN W. V. (1973) The Kranz syndrome in the Gramineae as indicated by carbon isotopic ratios. Amer. J. Bot. 60, 505-513. 
TULLOCH A. P. (1976) Chemistry of waxes of higher plants. In Chemistry and Biochemistry of Natural Waxes, (editor P. E. Kolattukudy), Elsevier, 236-287.

VAN DEVENDER T. R. and SPAULDING W. G. (1979) Development of vegetation - and climate in the southwestern United States. Science 204, 701-710. WATSON J. T. and BIEMANN K. (1964) High resolution mass spectra of compounds emerging from a gas chromatograph. Ana1. Chem. 36, 1135-1137. WEETE J. D. (1976) Alga1 and fungal waxes. In Chemistry and Biochemistry of Natural Waxes, (editor P. B. Kolattukudy), Elsevier, 350-418. WOOLHOUSE H. W. (1978) Light-gathering and carbon assimilation processes in photosynthesis; their adaptive modifications and significance for agriculture. Endeavor 2 (1), 35-46. 
Table 1. Plant $\delta^{13} \mathrm{C}$ values for dominant species in Pecos River Valley, New Mexico at elevations below $1219 \mathrm{~m}$ (4000 ft)

\begin{tabular}{|c|c|c|c|}
\hline Plant species & $\delta^{13} \mathrm{C}_{\mathrm{PDB}}(*)$ & Plant species & $\delta^{13} C_{\mathrm{PDB}}(*)$ \\
\hline Acacia neovernicosat & $-28.0 \pm 0.1$ & Flourensia cernuat & $-24.3 \pm 0.3$ \\
\hline Agave lecheguilla & $-10.8 \pm 0.5$ & Hilaria muticat & $-15.6 \pm 1.8$ \\
\hline Artemisia filifolia & $-27.7 \pm 0.4$ & Juglans microcarpa & $-30.4 \pm 1.3$ \\
\hline Aristida glauca申 . & $-12.4 \pm 0.4$ & Juniperus pinchotii & $-22.9 \pm 0.2$ \\
\hline A. Iongiseta & $-11.3 \pm 0.1$ & Krameria glandulosa : & $-22.3 \pm 0.1$ \\
\hline Atriplex canescenst & $-13.2 \pm 0.1$ & $\underline{\text { Larrea }}$ tridentataf & $-26.3 \pm 0.5$ \\
\hline Baccharis salicina & $-26.8 \pm 0.3$ & Lepidium montanum & $-28.1 \pm 0.2$ \\
\hline Bouteloua breviseta & $-12.7 \pm 0.1$ & Mimosa biuncifera & $-24.6 \pm 0.1$ \\
\hline B. curtipendula & $-14.0 \pm 0.1$ & Muhlenbergia arenacea & $-12.3 \pm 0.5$ \\
\hline B. eriopodatt & $-14.8 \pm 0.1$ & M. arenicolał & $-14.0 \pm 1.0$ \\
\hline B. gracilist & $-13.0 \pm 0.4$ & M. paucifloraf & $-13.6 \pm 0.1$ \\
\hline B. hirsutaf & $-13.4 \pm 0.1$ & M. porterit中 & $-15.1 \pm 0.1$ \\
\hline B. warnockiif & $-12.8 \pm 0.2$ & Nolina micrantha & $-21.7 \pm 0.2$ \\
\hline Bothriochoa springfieldii & $-11.6 \pm 0.1$ & Opuntia imbricata & $-12.3 \pm 0.9$ \\
\hline Brickellia laciniata & $-29.2 \pm 0.3$ & Parthenium incanum & $-26.8 \pm 0.2$ \\
\hline Chilopsis 1inearis & $-26.0 \pm 0.2$ & Panicum obtusum & $-12.4 \pm 0.6$ \\
\hline Condalia ericoides & $-25.5 \pm 0.8$ & Prosopis glandulosat & $-24.7 \pm 0.1$ \\
\hline Croton dioicus & $-28.5 \pm 0.1$ & Quercus havardii & $-25.1 \pm 0.1$ \\
\hline Distichlis spicata & $-13.6 \pm 0.1$ & Rhus microphyIla & $-22.7 \pm 0.1$ \\
\hline Eragrostis intermedia & $-12.5 \pm 0.8$ & \multicolumn{2}{|c|}{ Schleropogon brevifoliust中 $-14.2 \pm 0.5$} \\
\hline Erioneuron pilosum & $-13.3 \pm 0.4$ & Senecio douglasii & $-25.6 \pm 2.6$ \\
\hline E. pulchellumt & $-14.4 \pm 0.8$ & Setaria 1eucopila & $-12.1 \pm 0.1$ \\
\hline \multicolumn{4}{|c|}{$\begin{array}{l}* \delta^{13} C_{\mathrm{PDB}}=\left(\mathrm{R}_{\text {unknown }} / \mathrm{R}_{\mathrm{PDB}}-\mathrm{I}\right) \times 1000 \text {, where } \mathrm{R}={ }^{13} \mathrm{C} /{ }^{12} \mathrm{C} \text {. Uncertainties } \\
\text { expressed as one standard deviation. Values exceeding } 0.2 \text { permil reflect } \\
\text { actual }{ }^{13} \mathrm{C} \text { variations between different samples from the same plant. } \\
\text { tVery abundant } \\
\text { fGrass }\end{array}$} \\
\hline
\end{tabular}


Table 1. (Concluded)

\begin{tabular}{|c|c|c|c|}
\hline Plant species & $\delta^{13} C_{\mathrm{PDB}}\left({ }^{*}\right)$ & Plant species & $\delta^{13} C_{\mathrm{PDB}}{ }^{(*)}$ \\
\hline Sitanion Iongifolium & $-26.6 \pm 0.1$ & Tamarix pentandra & $-24.1 \pm 0.8$ \\
\hline Sorghum halepenset & $-12.1 \pm 0.1$ & Tidestromia lanuginosa & $-12.3 \pm 0.1$ \\
\hline Sporobolus airoidest $\neq$ & $-13.0 \pm 0.1$ & Tiguilia hispidissima & $-27.5 \pm 0.2$ \\
\hline s. cryptandrusf & $-12.9 \pm 0.1$ & Viguiera stenolobał & $-26.4 \pm 0.2$ \\
\hline S. Elexuosust & $-13.7 \pm 0.1$ & Xanthocephalum sarothraet & $-28.7 \pm 0.1$ \\
\hline S. nealleyi & $-14.9 \pm 0.4$ & Yucca elata & $-26.0 \pm 1.4$ \\
\hline S. wrightii伸 & $-12.2 \pm 0.1$ & Ziziphus obtusifolia & $-26.7 \pm 0.1$ \\
\hline
\end{tabular}

$\approx \delta^{13} C_{P D B}=\left(R_{\text {unknown }} / R_{P D B}-1\right) \times 1000$, where $R={ }^{13} \mathrm{C} /{ }^{12} \mathrm{C}$. Uncertainties expressed as one standard deviation. Values exceeding 0.2 permil reflect actual ${ }^{13} \mathrm{C}$ variations between different samples from the same plant. +Very abundant

非rass 
Table 2. $\delta^{13} C_{P D B}$ values and abundance (1977), of principal summer season crops, Eddy County, New Mexico

\begin{tabular}{lccc}
\hline Crop & Area, ha. & $\mathrm{C} 3$ & ${ }^{8{ }^{13} \mathrm{C}_{\mathrm{PD}}, \%}$ \\
\hline Alfalfa Hay & 11,300 & $-27.6 \pm 1.2$ & $\mathrm{C} 4$ \\
Corn & 465 & & $-13.4 \pm 0.2$ \\
Cotton, Upland & 6,350 & $-26.0 \pm 0.2$ & \\
$\begin{array}{l}\text { Sorghum } \\
\text { Average }\end{array}$ & 364 & $-13.0 \pm 0.3$ \\
Weighted total biomass* & & -26.8 & -13.2 \\
\end{tabular}

Source: New Mexico Agricultural Statistics (1977).

*Assumes uniform biomass per acre, regardless of crop type. 
Table 3. Normal hydrocarbons isolated from recent bat guano from the Carlsbad area, New Mexico

\begin{tabular}{|c|c|c|}
\hline Carbon number & Abundance* & $\delta^{13} \mathrm{C}_{\mathrm{PDB}}$ \\
\hline $15-20$ & $<1.0$ & - \\
\hline $2 I$ & 0.2 & - \\
\hline 22 & 0.1 & $-25.7 \pm 0.1$ \\
\hline 23 & 0.7 & $-24.1 \pm 0.1$ \\
\hline 24 & 0.2 & $-25.4 \pm 0.1$ \\
\hline 25 & 1.8 & $-22.2 \pm 0.1$ \\
\hline 26 & 0.4 & $-24.4 \pm 0.1$ \\
\hline 27 & 4.4 & $-23.0 \pm 0.1$ \\
\hline 28 & 0.9 & $-23.9 \pm 0.1$ \\
\hline 29 & 5.3 & $-23.2 \pm 0.1$ \\
\hline 30 & 0.9 & $-24.6 \pm 0.1$ \\
\hline 31 & 4.4 & $-24.3 \pm 0.1$ \\
\hline 32 & 0.7 & $-25.2 \pm 0.1$ \\
\hline 33 & 4.0 & $-23.8 \pm-0.1$ \\
\hline 34 & 0.4 & $-23.5 \pm 0.1$ \\
\hline 35 & 1.8 & $-23.2 \pm 0.1$ \\
\hline 36 & 0.2 & - \\
\hline 37 & 0.9 & $-23.1 \pm 0.1$ \\
\hline 38 & 0.1 & $-26.1 \pm 0.1$ \\
\hline 39 & 0.7 & $-22.8 \pm 0.1$ \\
\hline 40 & $\operatorname{tr}$ & - \\
\hline 41 & 0.7 & $-22.9 \pm 0.1$ \\
\hline 42 & $\operatorname{tr}$ & - \\
\hline 43 & $\operatorname{tr}$ & - \\
\hline
\end{tabular}

*Values denote the percentage by weight of the total alkane fraction. 
Table 4. Branched hydrocarbons isolated from recent bat guano from the Cárlsbad area, New Mexico

\begin{tabular}{lcc}
\hline Carbon Number & Abundance* & $\begin{array}{c}\text { Position of methyl } \\
\text { substituent }(s) \dagger\end{array}$
\end{tabular}

Monomethyl branched hydrocarbons

$\begin{array}{llll}26 & 0.2 & 3 ; 7 ; 9 ; 11 ; \text { or } 13 & -22.0 \pm 0.1 \\ 27 & 0.1 & 2 & -24.8 \pm 0.1 \\ 28 & 1.1 & 3 ; 7 ; 9 ; 11 ; \text { or } 13 & -23.1 \pm 0.1 \\ 29 & 0.2 & 2 & -23.1 \pm 0.1 \\ 30 & 2.6 & 3 ; 9 ; 11 ; 13 ; \text { or } 15 & - \\ 31 & 0.4 & 2 & -23.5 \pm 0.1 \\ 32 & 4.4 & 9 ; 11 ; 13 ; \text { or } 15 & -20.7 \pm 0.1 \\ 33 & 0.9 & 2 & -20.2 \pm 0.1 \\ 34 & 5.3 & 9 ; 11 ; 13 ; 15 ; \text { or } 17 & -23.2 \pm 0.1 \\ 35 & 0.1 & 2 & -20.1 \pm 0.1 \\ 36 & 2.2 & 11 ; 13 ; 15 ; 17 ; \text { or } 19 & -20.1 \pm 0.1\end{array}$

Dimethyl branched hydrocarbons

\begin{tabular}{|c|c|c|c|}
\hline 37 & 4.0 & 11,$15 ; 13,17$; or 15,19 & - \\
\hline 39 & 5.3 & $\begin{array}{l}9,13 ; 11,15 ; 13,17 ; \text { or } \\
15,19\end{array}$ & $-20.0 \pm 0.1$ \\
\hline 41 & 4.4 & $\begin{array}{l}11, .15 ; 13,17 ; 15,19 ; \\
\text { or } 17,21\end{array}$ & $-19.6 \pm 0.1$ \\
\hline 43 & 3.5 & 11,$15 ; 13,17 ;$ or 15,19 & $-22.8 \pm 0.1$ \\
\hline 45 & 4.9 & 11,$15 ;$ or 13,17 & $-20.8 \pm 0.1$ \\
\hline 47 & 4.4 & 11,$15 ;$ or 13,17 & $-24.8 \pm 0.1$ \\
\hline 49 & 4.0 & - & $-23.9 \pm 0.1$ \\
\hline 51 & 3.5 & - & $-23.8 \pm 0.1$ \\
\hline
\end{tabular}

*Values denote percentage by weight of total alkane fraction. tNumbers separated by semicolons describe individual components of a mixture. 
Table 5. Mean $\delta^{13} C_{\mathrm{pDB}}$ values for plants and bat guano hydrocarbons

\begin{tabular}{|c|c|c|c|}
\hline . & \multirow[t]{2}{*}{ Substance } & \multicolumn{2}{|c|}{ Mean $\delta^{13} \mathrm{C}_{\mathrm{PDB}}$} \\
\hline & & Weighted & Unweighted \\
\hline \multirow[t]{7}{*}{ Plant } & 58 nonagricultural species & - & $-19.2 \pm 6.7$ \\
\hline & 13 most dominant species & - & $-19.0 \pm 6.2$ \\
\hline & 27 C3 species & - & $-26.0 \pm 2.2$ \\
\hline & $31 \mathrm{C} 4$ and CAM species & - & $-13.1 \pm 1.1$ \\
\hline & 29 grass species & - & $-14.3 \pm 3.7$ \\
\hline & 29 nongrass species & - & $-24.1 \pm 5.3$ \\
\hline & 4 abundant summer crops & -26.2 & $-20.0 \pm 7.9$ \\
\hline \multirow[t]{10}{*}{ Guano } & BuIk guano & - & $-20.1 \pm 0.4$ \\
\hline & Total hydrocarbons & -22.7 & $-23.0 \pm 1.7$ \\
\hline & Al1 normal aIkanes & -23.6 & $\overline{-24.0} \pm 1.1$ \\
\hline & Odd carbon normal alkanes & -23.4 & $-23.3 \pm 0.6$ \\
\hline & Even carbon normal alkanes & -24.6 & $-24.9 \pm 0.9$ \\
\hline & Al1 branched chain alkanes & -21.9 & $-22.2 \pm 1.8$ \\
\hline & Monomethyl branched alkanes & - & $-22.1 \pm 1.8$ \\
\hline & Dimethyl branched alkanes & - & $-22.2 \pm 2.1$ \\
\hline & "Heaviex" branched alkanes & - & $-20.2 \pm 0.4$ \\
\hline & "Lighter" branched alkanes & - & $-23.7 \pm 0.7$ \\
\hline
\end{tabular}




\section{FIGURE CAPTIONS}

Fig. 1. Procedure for the isolation and identification of bat guano a.lkanes (see MITCHELL, 1972).

Fig. 2. Plots of abundances of plant species or insect alkanes versus their $\delta^{13} C_{\mathrm{PDB}}$ values. Abundances were determined by totaling $\delta^{13} \mathrm{C}_{\mathrm{PDB}}$ values within \pm 0.5 permil of -10 permil, -10.5 permil, -11 permil, and so forth. It sould be noted that each $\delta^{13} \mathrm{C}_{\mathrm{PDB}}$ value is counted twice in this procedure. (a) Abundances of nonagricultural plants in the Pecos River Valley, New Mexico, versus their $\delta^{13} C_{\mathrm{PDB}}$ values. Mean $\delta^{13} C_{\mathrm{PDB}}$ for all plants is indicated as a vertical black bar on the horizontal axis. Shaded portions of the histogram depict the distribution of the most abundant plants in the ecosystem. (b) Abundances of dominant agricultural plants in the Pecos River Valley versus their $\delta^{13} \mathrm{C}_{\mathrm{PDB}}$ for 1977 biomass is indicated as a vertical black bar on the horizontal axis. (c) Abundances of guano alkanes versus their $\delta^{13} \mathrm{C}_{\mathrm{PDB}}$ values. Branched alkanes are represented by the solid lines; the $\underline{n}$-alkanes are represented by the dashed lines.

Fig. 3. Plots of (a) abundance and (b) $\delta^{13} C_{P D B}$ values of branched alkanes versus their carbon numbers, Histogram bars and data points designate the hydrocarbons as follows: isoalkanes (white bars, o), monomethyl internally branched alkanes (black bars, ${ }^{\circ}$ ) and dimethyl internally branched alkanes (shaded bars, $\Delta$ ).

Fig. 4. Diagram representing the flows and isotopic compositions of carbon in a simplified ecosystem including only a single plant species 
and a single insect species. The term "branched alkanes" refers specifically to the branched structures made selectively by insects (see Table 4). The isotopic fractionations and mixing processes indicated are discussed in the text.

Fig. 5(a). Diagram representing the flows and isotopic compositions of bulk carbon and of branched alkanes in the plant-insect-bat ecosystem studied in this work. The existence of two isotopically distinct families of branched alkanes is used to infer the existence of two isotopically distinct insect populations that must have isotopically distinct diets derived from differing proportions of $\mathrm{C} 3$ and $\mathrm{C} 4$ plants.

Fig. 5(b). Diagram representing the isotopic mixing processes leading. to the odd-carbon-number and even-carbon-number $\mathfrak{n}$-alkane proportions observed in the guano. The normal alkanes synthesized by insects are assumed to be equal in isotopic composition to the branched alkanes synthesized by the same insect populations. 


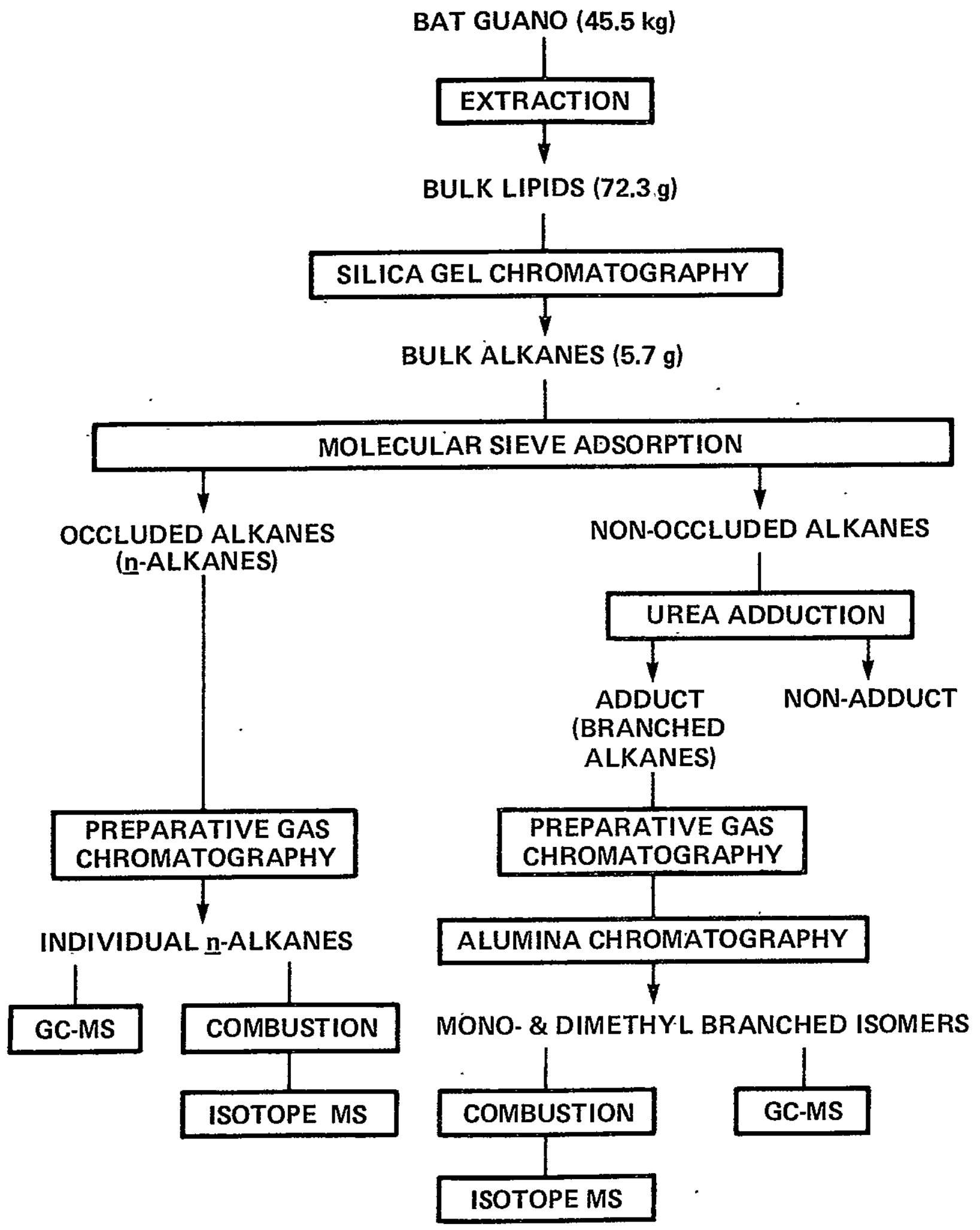

Fig. I 


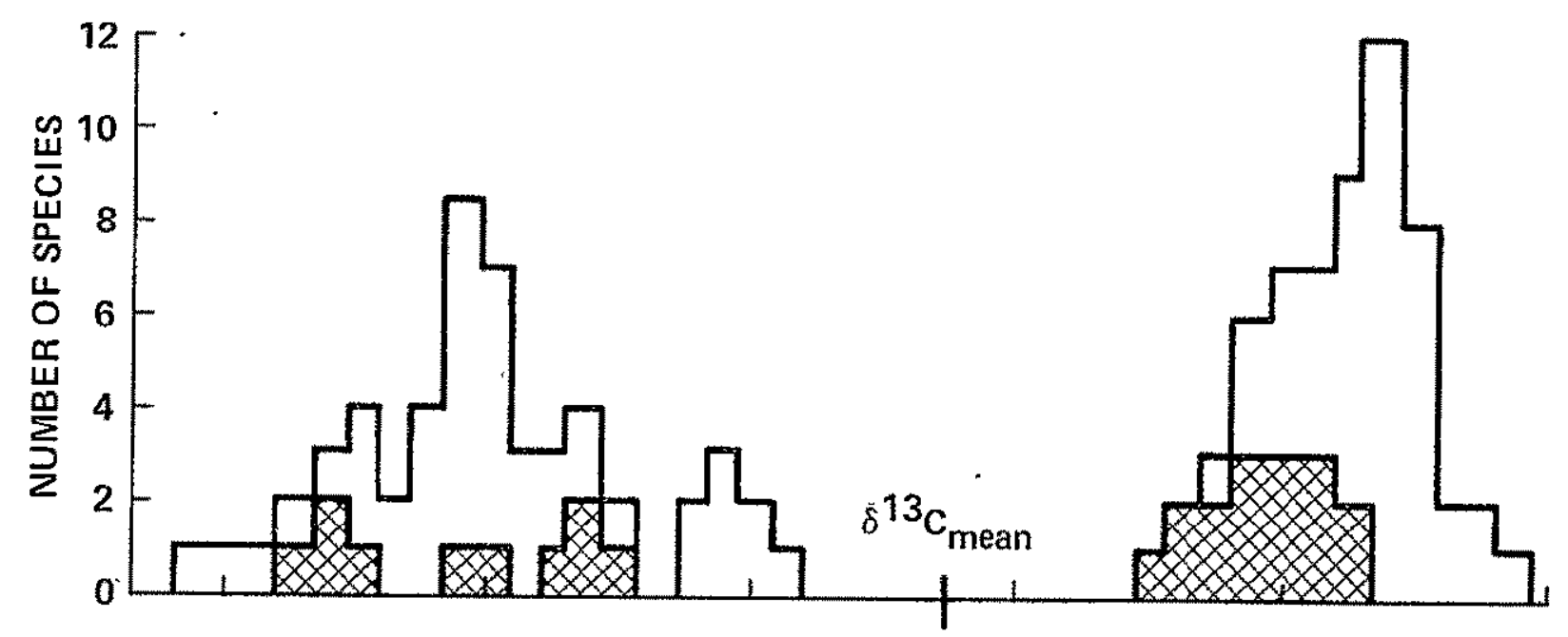

(a)
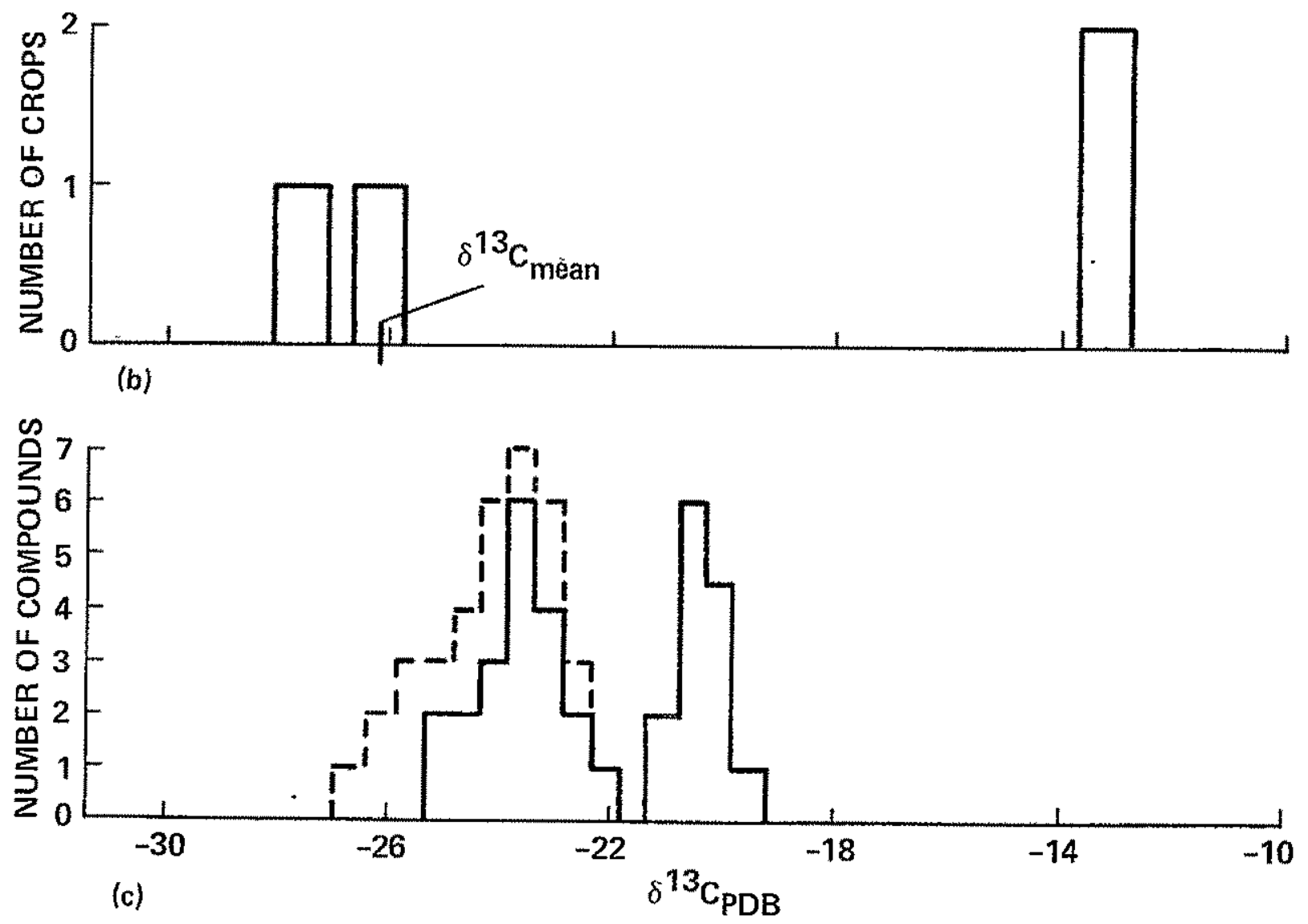

F施。 2 


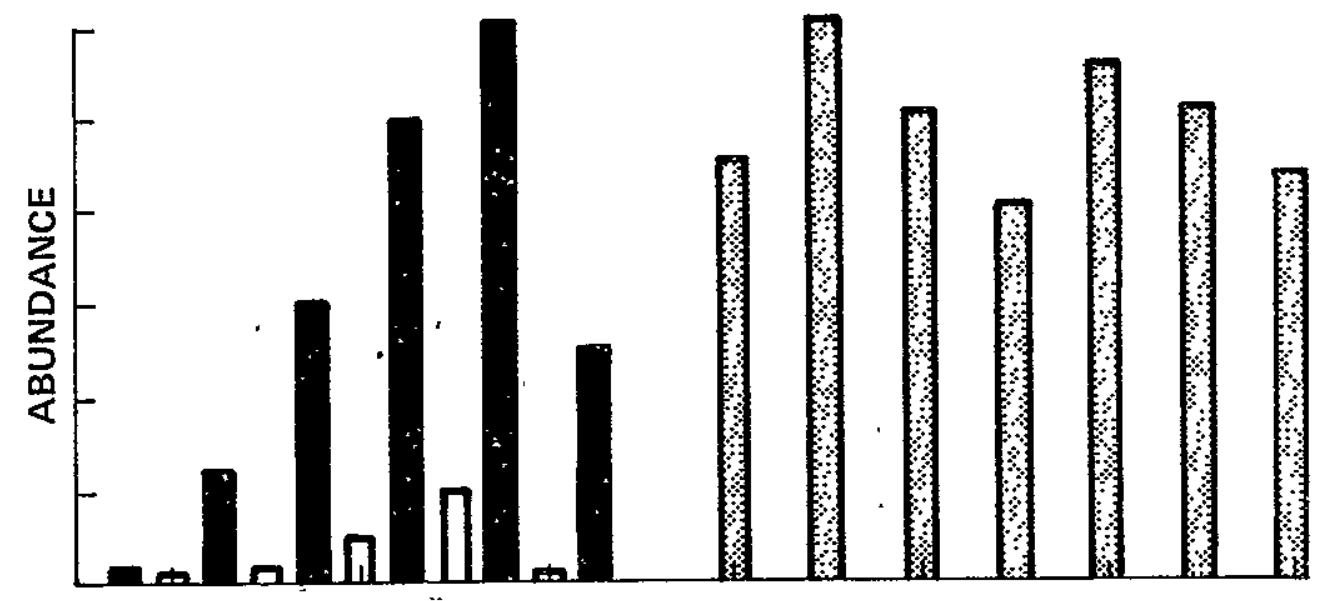

(a)

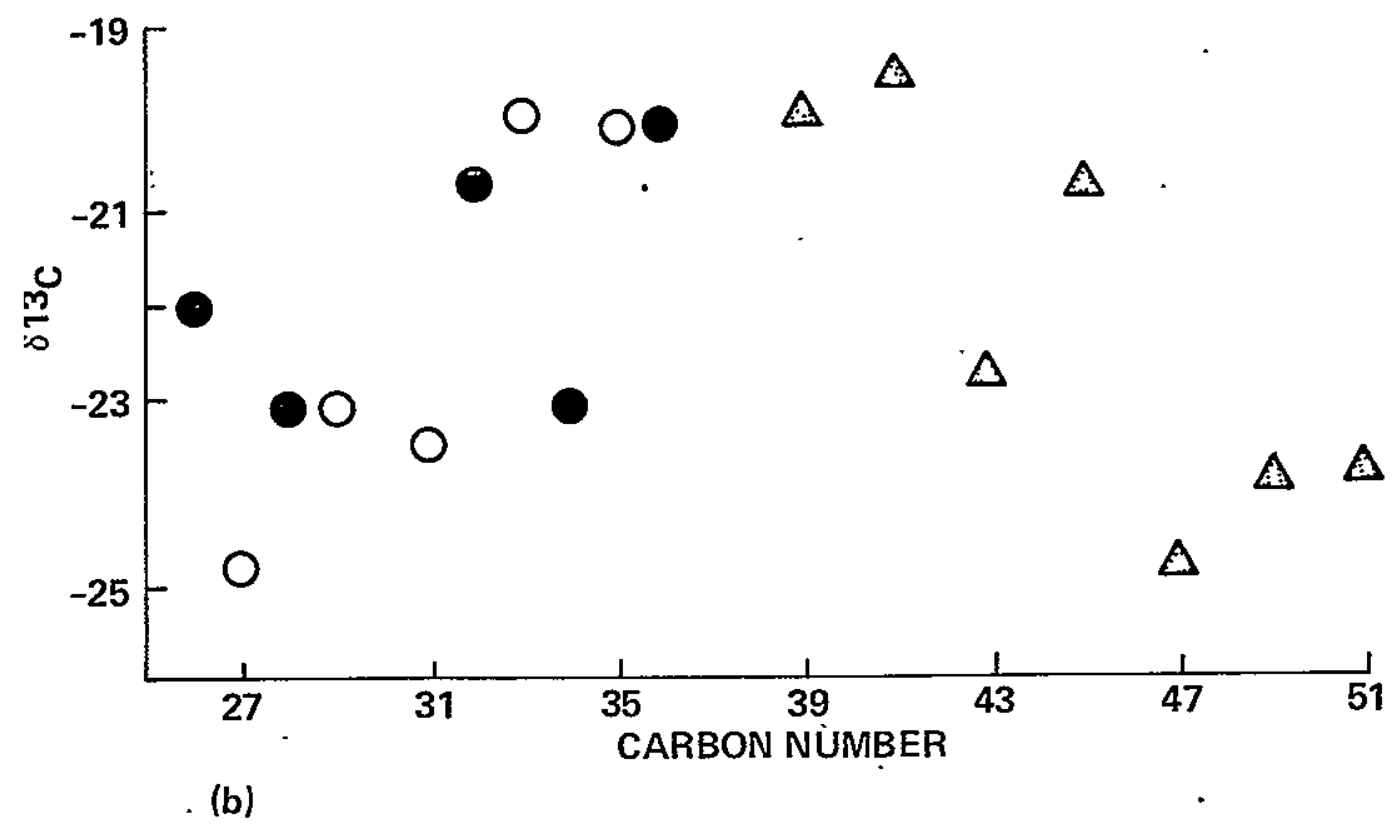

Fig. 3 


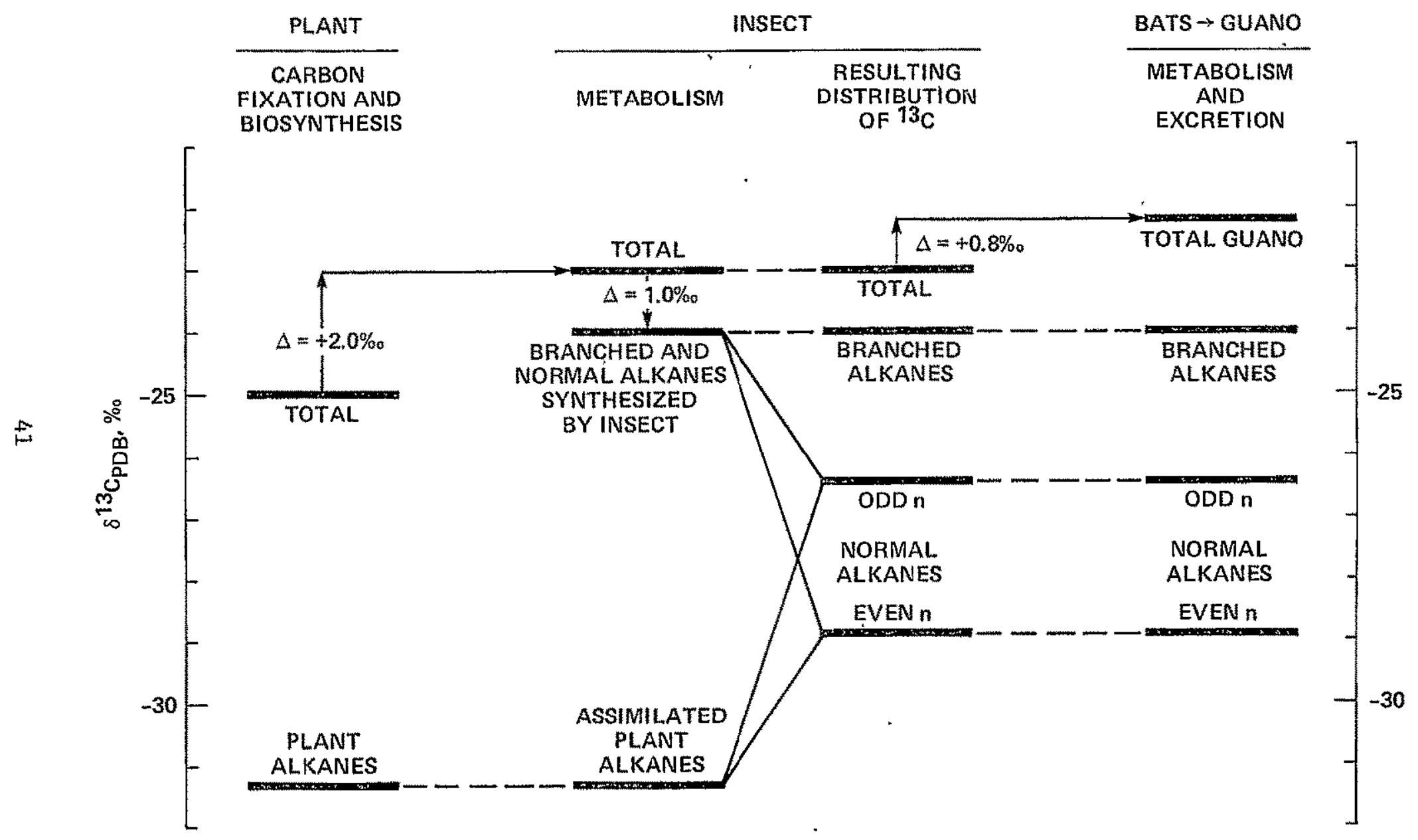

Fig. 4 


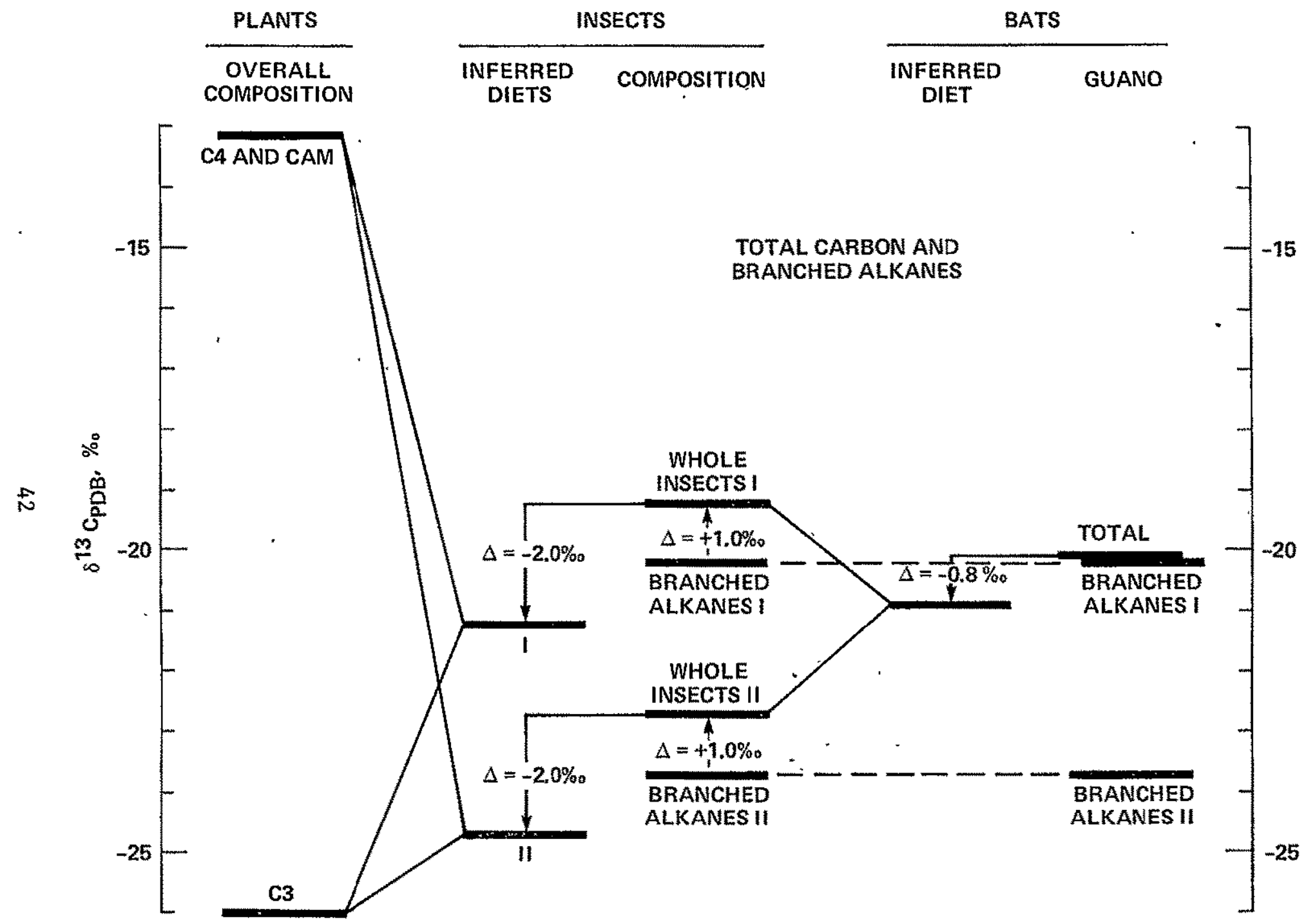

Fig. 5(a) 

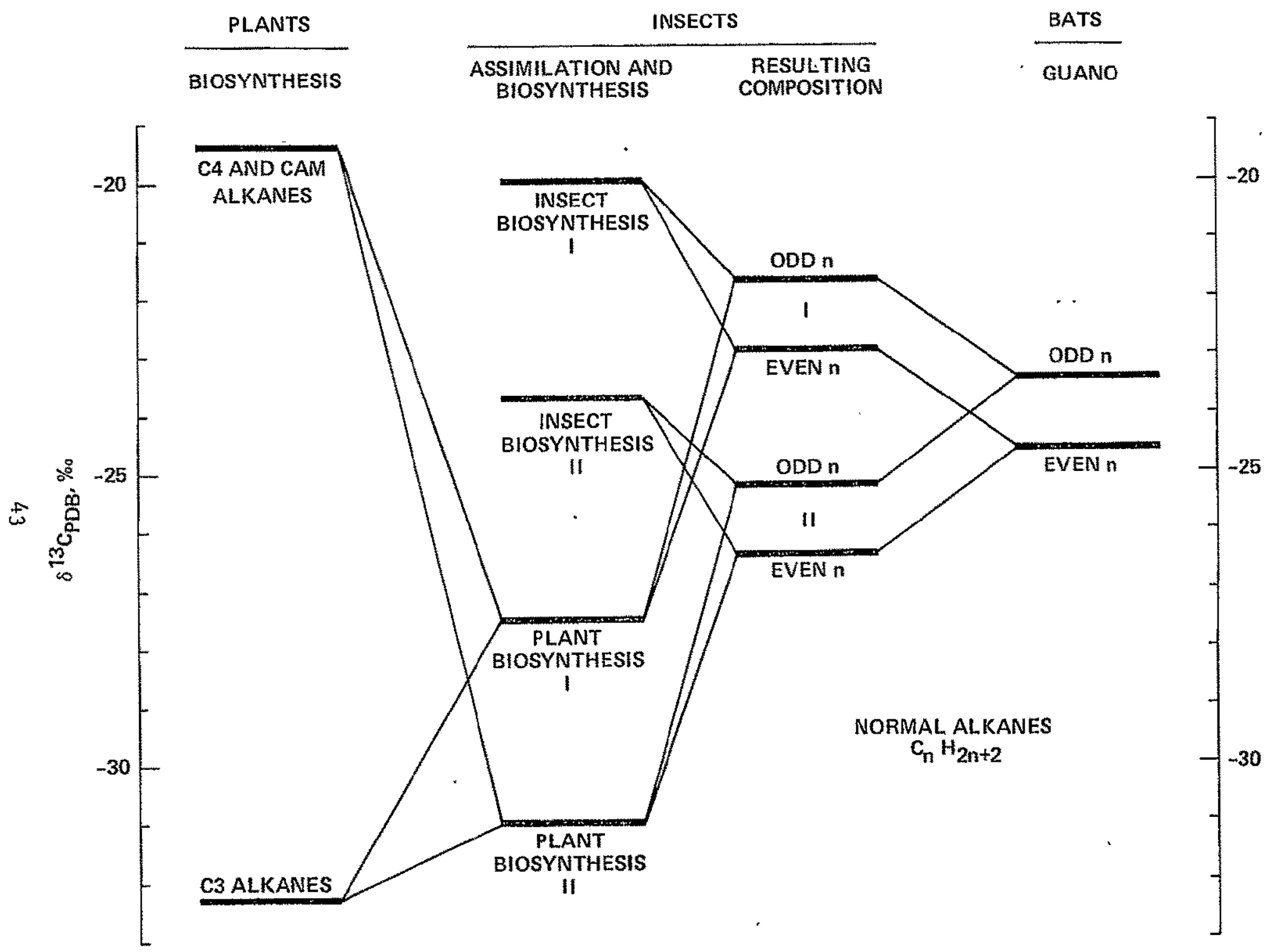

Fig. 5(b) 


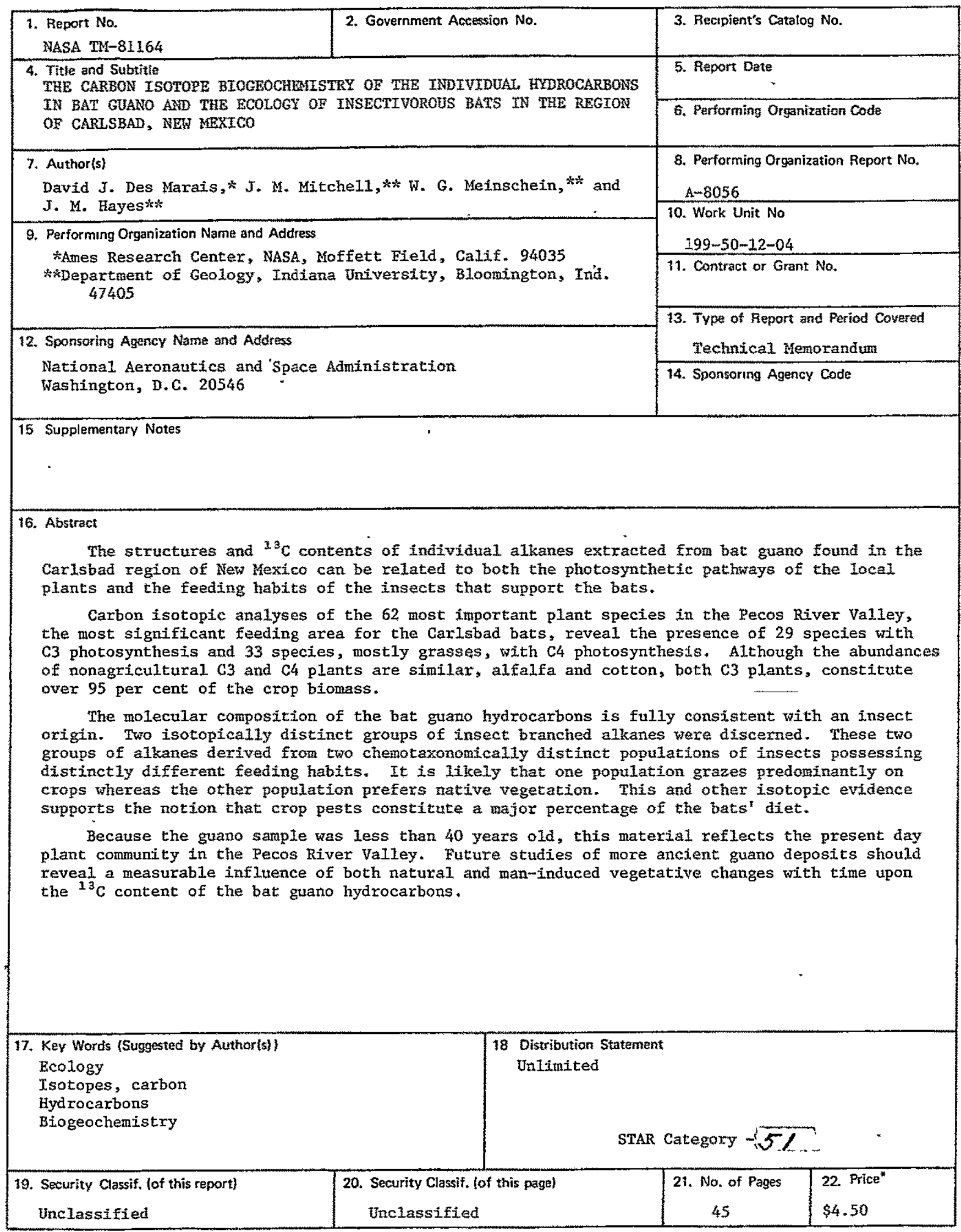

